Satya Widya : Jurnal Studi Agama Vol. 3 No. 12020

$P-I S S N$ : 2623-0534

E-ISSN : 2655-1454

Website Jurnal : https://ejournal.iahntp.ac.id/index.php/satya-widya/index

DOI: https://doi.org/10.33363/swjsa.v3i1 Juni.439

\title{
ESENSI PERAYAAN SIWARATRI: Konsep dan Implementasinya dalam Konstruksi Pengetahuan Keagamaan Menuju Pencerahan
}

\author{
I Made Pasek Subawa \\ Institut Hindu Dharma Negeri (IHDN) Denpasar \\ imadepaseksubawa@gmail.com
}

\begin{abstract}
Riwayat Jurnal
Artikel diterima: 27 Januari 2020

Artikel direvisi: 24 Februari 2020

Artikel disetujui: 28 Maret 2020
\end{abstract}

\begin{tabular}{|l|l|}
\hline Kata Kunci: & \multicolumn{1}{|c}{ Perayaan Siwaratri dapat dinayatakan sebagai } \\
Siwaratri, & Konnstuksi \\
pengetahuan, & sebuah konstruksi sosial-religi, hal ini mengingat adanya \\
pencerahan & unsur eksternalisasi dalam wujud sebuah konsep Siwaratri, \\
objektivasi (pelembagaan proses ritual dan disiplin diri \\
untuk memuja Tuhan dalam manisfestasinya sebagai \\
pemralina), dan internalisasi yakni penyerapan nilai dan \\
norma dalam Perayaan Siwaratri sebagai fondasi dalam \\
mewujudkan konsolidasi harapan, keyakinan, kebangkitan \\
sikap mental menuju pencerahan dan liberasi. \\
Proses konstruksi dilakukan dengan menyusun \\
kembali informasi tentang Siwaratri baik yang berupa \\
pengetahuan, keyakinan, kepercayaan, nilai-nilai dan \\
sikap, tradisi-tradisi, serta pola-pola tindakan tertentu yang \\
diperoleh dalam praktek keagamaan ini menjadi satu \\
struktur informasi yang powerful, dalam arti bermakna, \\
berbasis nilai-nilai, terintegrasi dan selalu aktif \\
memandang untuk selalu dapat direfleksikan kembali. \\
Pengetahuan dan keyakinan mengenai Siwaratri bukanlah \\
realitas objektif yang ada di luar diri manusia, melainkan \\
rekonstruksi aktif dalam pikiran manusia ketika \\
berinteraksi dalam kehidupan beragama dan sekaligus \\
keyakinan itu dapat membangun kembali pengetahuan, \\
nilai-nilai, dan tindakan tertentu yang berguna bagi subjek \\
(umat Hindu) terutama dalam membangun kesalehan \\
personal, struktural, dan sosial.
\end{tabular}




\begin{tabular}{|l|l|}
\hline $\begin{array}{l}\text { Construction of } \\
\text { knowledge, } \\
\text { enlightenment }\end{array}$ & $\begin{array}{l}\text { form of a Siwaratri concept, objectivation (institutionalization of } \\
\text { ritual processes and self-discipline to worship God in its } \\
\text { manifestation as a memalina), and internalization, namely the } \\
\text { absorption of values and norms in Siwaratri Celebration. as a } \\
\text { foundation in realizing the consolidation of hopes, beliefs, } \\
\text { awakening mental attitude towards enlightenment and liberation. } \\
\text { The construction process is carried out by rearranging } \\
\text { information about Siwaratri in the form of knowledge, beliefs, } \\
\text { beliefs, values and attitudes, traditions, and patterns of certain } \\
\text { actions obtained in this religious practice into a powerful } \\
\text { information structure, in a meaningful sense, based on values, } \\
\text { integrated and always actively looking to always be reflected } \\
\text { back. Knowledge and beliefs about Siwaratri are not objective } \\
\text { realities that exist outside of humans, but active reconstruction in } \\
\text { the human mind when interacting in religious life and at the } \\
\text { same time these beliefs can rebuild certain knowledge, values, } \\
\text { and actions that are useful for the subject (Hindus) especially in } \\
\text { building personal, structural, and social piety. }\end{array}$ \\
\hline
\end{tabular}

\section{Pendahuluan}

Pelaksanaan suatu upacara dalam ritual Hindu bukan dilaksanakan tanpa motif atau tidak muncul tiba-tiba, namun pelaksanaannya berakar pada suatu kepercayaan, tradisi dan norma-norma agama serta dilandasi oleh tujuan yang jelas. Eksistensi sebuah ritual merupakan sebuah media yang sarat dengan makna simbolik yang menghubungkan dunia nyata dengan alam gaib, yang konkrit dan abstrak, sorga dan neraka, manusia dan Tuhan. Demikian pula eksistensi sebuah ritual dalam Siwaratri didalamnya terdapat unsur-unsur sakral, kepercayaan-kepercayaan, mythology, pengalaman-pengalaman sembahyang dari setiap individu.

Upacara-upacara keagamaan tidak hanya sekedar eksis, tetapi dapat berfungsi sebagai sarana yang memperkuat dan mengukuhkan keyakinan. Sementara itu Durkheim (1966:62) berpendapat bahwa:

"A religion is a unified system of beliefs and practices relative to sacred things, that is to say, thing set apart and forbidden beliefs and practices which unite into one single moral community called a Church, all those who adhere to them".

Dari definisi tersebut dapat dilihat bahwa bagi Durkheim agama ialah suatu sistem terpadu yang terdiri atas kepercayaan dan praktek keagamaan yang berhubungan dengan hal-hal yang suci dan sakral, dan bahwa kepercayaan dan praktek itu berfungsi sebagai pemersatu bagi semua orang yang beriman ke dalam suatu komunitas moral yang dinamakan umat. Kemudian ditambahkan pula oleh Durkheim bahwa, semua kepercayaan agama mengenal semua benda yang ada di bumi ini, baik yang berwujud nyata maupun ideal ke dalam dua kelompok yang $14 \mid$ 
Satya Widya : Jurnal Studi Agama Vol. 3 No. 12020

$P$-ISSN : 2623-0534

E-ISSN : 2655-1454

Website Jurnal : https://ejournal.iahntp.ac.id/index.php/satya-widya/index

DOI: https://doi.org/10.33363/swjsa.v3i1 Juni.439

antagonis baik yang bersifat profan maupun yang bersifat sakral (Durkheim, 1966:52).

Kepercayaan keagamaan tidak hanya melukiskan dan menjelaskan makhlukmakhluk sakral dan alam gaib, Tuhan dan segala manifestasinya, sorga dan neraka, tetapi yang lebih penting dari semua itu adalah kepercayaan-kepercayaan itu menjelaskan bagaimana alam gaib dihubungkan dengan dunia manusia yang nyata (Nottingham, 1994:14). Dengan kata lain, bagaimana alam gaib yang diidealkan dalam agama Hindu itu dapat dicapai melalui suatu ritual yang telah ditetapkan dalam agama.

Dunia gaib bisa dihadapi manusia dengan berbagai perasaan seperti; cinta, hormat, bhakti, tetapi juga takut, ngeri dan sebagainya. Perasaan-perasaan tadi mendorong manusia untuk melakukan berbagai perbuatan ritual yang bertujuan untuk mencari hubungan dengan dunia gaib, berupaya mencari solusi dengan melakukan kontemplasi (perenungan) melalui meditasi atau dengan melakukan tapa brata, sehingga mencapai enlightment (pencerahan) dan liberasi atas sesuatu yang diyakini sebagai suatu dosa atau kekeliruan menurut perspektif agama. Kecuali itu di dalam hal melakukan kelakuan-kelakuan keagamaan itu, manusia selalu dihinggapi oleh suatu emosi keagamaan. Kelakuan keagamaan yang dilakukan menurut tata kelakuan yang baku disebut upacara keagamaan atau religious ceremonies atau rites. Adapun komponen-komponen dari sistem upacara keagamaan terdiri dari; 1) Tempat Upacara, 2) Saat Upacara, 3) Orang-orang yang melakukan Upacara dan memimpin Upacara, dan 4) Benda dan alat-alat upacara (Koentjaraningrat, 1974:221).

Agama Hindu sebagai sebuah religi tidak ada bedanya dengan agama lain terutama apabila dilihat dari unsur-unsur dasar yang terdapat dalam religi itu, sebagaimana diungkapkan oleh Light, Keller dan Calhoun (1989:518-521) yang meliputi: kepercayaan agama, simbol-simbol agama, praktek agama, umat agama, dan pengalaman agama. Bila unsur tersebut tidak terpenuhi, maka dapat disebut sebagai civil religion, menurut konsep Robert Bellah dalam Kornblum (1988:500). Konsep civil religion terlihat dalam kegiatan-kegiatan seperti; pledge of allegiance, upacara bendera, menyanyikan lagu Indonesia Raya, dan lain-lain.

Setiap agama mempunyai unsur-unsur dasar sebagai terdapat dalam sistem upacara keagamaan tersebut. Dalam konteks kehidupan agama Hindu, unsur kepercayaan secara inheren dan implicit terdapat dalam konsep ajaran Pasca Sraddha, yang didukung oleh praktek-praktek keagamaan dalam bentuk ritual yang bersumber pada ajaran sraddha itu. Praktek-praktek keagamaan yang manifest dalam bentuk ritual atau upakara itu memperlihatkan adanya simbol-simbol yang sarat makna dan sebagai media penghubung antara yang konkrit dan abstrak, antara dunia manusia dan dunia gaib. Bahasan mengenai masalah Siwaratri tampaknya merupakan kajian yang selalu menarik untuk dijadikan sebagai bahan renungan untuk pendalaman akan makna simbolik yang melekat dalam sistem religi itu.

Bahasan mengenai makna simbolik siwaratri dipandang masih cukup urgent/essential, meskipun demikian dalam sikus interaktif perlu pula disinggung mengenai kepercayaan dan praktek-praktek keagamaannya. Telaah mengenai 
masalah Siwaratri bertumpu pada kajian teks keagamaan dan analisis dari para cendikiawan Hindu yang memiliki pemahaman yang lebih komprehensif mengenai Siwaisme dan perayaan Siwaratri. Dalam konteks sekarang ini, pemaknaan hari suci Siwaratri tidak saja terkait secara tekstual, akan tetapi bagaimana memaknainya dengan perilaku yang mampu memberikan konstruksi pengetahuan untuk dapat menyadarkan manusia akan nilai dan makna yang sarat dengan pesan-pesan moral. Sehubungan dengan hal itu, penulis harus mengatakan bahwa "if I have seen further, it is by standing on the shoulder of the giants".

\section{Pembahasan}

\section{Konsepsi Siwaratri}

Sudah umum diketahui bahwa sehari sebelum tilem sasih kepitu umat Hindu merayakan suatu hari suci yang disebut dengan hari suci Siwaratri. Sudah banyak diskusi digelar untuk menelusuri hakikat dan makna filosofis perayaannya. Bahkan sempat menjadi polemik, walaupun pada akhirnya ditemukan makna esensialnya. Bahwa Siwaratri adalah malam renungan suci, tidak lagi disebut sebagai hari peleburan dosa, meskipun pada hari itu merupakan hari untuk pemujaan kepada Dewa Siwa dalam manifestasi Tuhan sebagai Dewa Pemralina.

Konsep Siwaratri berasal dari dua kata, yakni Siwa dan ratri. Kata Siwa berarti; yang memberi keberuntungan, yang baik hati, ramah, suka memaafkan, menyenangkan, memberi banyak harapan, yang tenang membahagiakan dan sejenisnya (Monier, dalam Titib,2000:239). Sang Siwa dalam menggerakkan hukum kemahakekuasaan-Nya didukung oleh sakti-Nya yaitu Durga atau Parvati. Dewa Siwa dianggap sebagai salah satu dari trinity atau lebih sering dikenal dengan istilah Tri Murti, dalam sifat Tuhan sebagai pelebur/pemrelina. Sedangkan kata ratri berarti malam (saat gelap).

Dengan demikian secara harfiah, konsep Siwaratri dapat diterjemahkan sebagai hari suci sebagai malam yang tergelap pada panglong ping 14 untuk memuja Siwa. Konstruksi pemahamanan publik (umat Hindu) melalui perayaan Siwaratri dianggap sebagai saat yang tepat untuk memuja Dewa Siwa sebagai dewa yang memiliki fungsi sebagai pemralina khususnya melebur segala dosa. Lagi pula, ada argumen yang kuat bahwa sifat Tuhan (khususnya Siwa)yang maha pengampun, yang baik hati, ramah, suka memaafkan, menyenangkan, memberi banyak harapan, yang tenang membahagiakan, menjadi alasan mengapa perlu mengadakan renungan suci kepada Siwa, meskipun diakui bahwa konstruksi pelaksanaan pemujaan Siwa melalui perayaan Siwaratri juga dilandasi oleh cerita Lubdaka.

Konsep Siwaratri mengacu kepada beberapa sumber sebagai rujukan seperti : Siwa Purana (bagian Jnanasamhita), Skanda Purana (bagian Kedakarakanda), Garuda Purana (bagian Acarakanda), Padma Purana (bagian Uttara Kanda), dan Kekawain Jawa kuna Siwaratrikalpa karya Mpu tanakung, yang ternyata karya kekawin ini bersumber pada Padmapurana. Uraian siwaratrikalpa juga ditemukan dalam lontar Ajibrata serta sejumlah kidung dan geguritan Lubdhaka (Agastya,1997:1). 
Satya Widya : Jurnal Studi Agama Vol. 3 No. 12020

$P$-ISSN : 2623-0534

E-ISSN : 2655-1454

Website Jurnal : https://ejournal.iahntp.ac.id/index.php/satya-widya/index

DOI: https://doi.org/10.33363/swjsa.v3i1 Juni.439

\section{Implementasi Perayaan Siwaratri}

Pelaksanaan Siwaratri (khususnya di Bali) diimplementasikan dalam bentuk disiplin diri dan ritual melalui 3 (tiga) fase kegiatan yakni; siang hari pertama, malam hari, dan keesokannya, yang meliputi kurun waktu 36 jam (dua hari dan satu malam). Proses kegiatannya berdasarkan atas Kekawin Siwaratri Kalpa yang memuat dialog antara Dewi Uma dengan Dewa Siwa yang dibungkus dengan cerita Lubdaka, bahwa upacara Siwaratri dimulai pada pagi hari setelah melakukan pemujaan "Puja Surya Sewana" (pemujaan menjelang terbitnya matahari di ufuk timur pada pagi hari). Demikian pula awal persiapan pelaksanaan pemujaan didahului dengan asuci laksana atau menyucikan diri.

Pada siang harinya upacara dilakukan dengan pemujaan kepada Dewa Siwa dalam wujud Siwagni. Setelah melakukan pemujaan pelaksanaan selanjutnya adalah mentaati dan melakukan pantangan-pantangan "...teher duluranopawasa saha mona..." yang berua jagra, upawasa dan mona brata. Ketiga pantangan ini merupakan pantangan-pantangan yang patut dilaksanakan dalam pelaksanaan Siwaratri. Tidak dapat dipungkiri bahwa, pada pantangan-pantangan itu menampakkan adanya nilai-nilai kesucian dan menambah kemantapan dalam pelaksanaan ritual Siwaratri.

Upawasa atau puasa berarti berpantangan terhadap makanan yang tidak sattvik apapun jenisnya. Makna sesungguhnya dari berpuasa adalah mengendalikan semua organ rasa atau indera dan menghindarkannya dari hal-hal yang buruk atau tidak diinginkan. Hal itu bukanlah berarti hanya tidak makan atau tidak makan nasi seperti yang dipikirkan oleh kebanyakan orang. Kata Sansekerta untuk puasa adalah upavasa. Kata itu mengandung makna yang sangat mendalam, upa berarti dekat dan vasa berarti tinggal. Jadi upavasa berarti tinggal dekat atau hidup dekat. Hidup dekat dengan siapa? Tentu saja dengan Tuhan. Pikiran mesti tetap tertuju pada Tuhan dan pada setiap kesempatan, ketika terjaga, makan, minum, berjalan dan sebagainya meski tetap memanggil Tuhan. Dengan demikian berarti kita hidup dekat dengan Tuhan. Upavasa berarti terus menerus merasakan kehadiran Tuhan di dalam mengembangkan hubungan yang semakin dekat dengan-Nya. Inilah makna sesungguhnya dari puasa. Dengan demikian puasa bukan berarti hanya sekedar mengosongkan perut atau berpantang untuk tidak makan makanan tertentu, namun bila pikiran menerawang kemanamana dan tidak tertuju kepada Tuhan, bukanlah Puasa (Mantra, 1999: 20-23).

Puasa juga hendaknya menyangkut aspek yang holistik dan bukan hanya mengendalikan lidah, tetapi juga harus mampu mengendalikan 3T yakni: taste buds atau rasa, talk atau bicara, dan temper atau karakter. Bila mampu berpuasa dengan mengendalikan 3T tersebut maka akan mampu mengendalikan indria yang kemudian mampu menuntutn dan mengendalikan pikiran menjadi calm dan die mind sehingga dapat diarahkan untuk memahami Tuhan dengan lebih jernih.

Selanjutnya, setelah melewati kurun waktu 12 jam pada siang hari pertama yang dilakukan dengan upawasa dan mona brata, brata Siwaratri pada malam hari bertambah satu lagi yakni dengan melakukan jagra (tidak tidur) yang disebut pula dengan istilah tan mrema, atanghi atau aturu. Diantara ketiga pantangan itu, 
tampaknya pantangan untuk melakukan jagra lebih ditekankan dalam pelaksanaan Siwaratri secara keseluruhan. Makna di balik itu tentu diharapkan adanya kesadaran diri disamping penguasaan diri sendiri. Mengenai hal itu, dalam Kekawin Kalpa, bait 5-6, dinyatakan bahwa:

Saka ri maha prabhawa nikana ng bratanya Siwarartri tan hana mada/

Ikan ng atanghi ring wengi catur dasi kapitu krsna paksa ya tika /

Atisaya ring mahottama luput sakeng kawah awas musir siwa-pada//

Terjemahannya:

Berkat kebesaran prabawa dari brata Siwaratri yang tiada tara /

Maka seorang yang bergadang pada malam ke empat belas paro gelap dari bulan ke tujuh adalah /

Sangat mulia dalam keutamaan sehingga uput dari neraka dan tentu akan mencapai sorga //

Ketika sedang melakukan ketiga pantangan itu, diwajibkan pula untuk mengandalkan pemujaan yang ditujukan kepada Bhatara Siwa Lingga yang bersemayam di Suralaya. Demikian pula ditujukan kepada Bhatara Kumara terutama Bhatara Gana. Pemujaan terhadap Dewa Siwa agaknya memperkuat dugaan bahwa Siwaratri merupakan upacara Dewa Yadnya, oleh karena itu maka sikap dan norma dalam persembahyangan Siwaratri juga disesuaikan dengan sikap dan aturan prilaku dalam persembahyangan upacara Dewa Yadnya.

Dalam pelaksanaan upacara Siwaratri, juga dibenarkan untuk melakukan kontemplasi atau perenungan dalam bentuk semadi atau meditasi dengan melakukan pemusatan pikiran kepada dewa-dewa pujaan (istha dewata) sehingga dapat menambah kidmat dalam melaksanakan renungan suci pada hari Siwaratri. Sebagai penawar rasa kantuk, dalam pelaksanaan Siwaratri juga dibenarkan untuk mengadakan malam kesenian dan permainan. Diantaranya adalah kesenian yang dapat dinikmati seperti; kidung, kekawin, pementasan drama, membaca kitab suci, pementasan sendratari dan bahkan film-film yang bernuansa spiritual dan keagamaan seperti epic Ramayana dan Mahabharata dapat ditampilkan pada Siwaratri itu. Hal yang lebih penting adalah pengkajian akan makna Siwaratri itu melalui kegiatankegiatan dharma thula, dharma wacana, dharma gita dan lain-lain.

Kegiatan yang juga direkomendasi oleh sastra agama untuk dilakukan dalam rangkaian pelaksanaan Siwaratri adalah melakukan dana punia. Hal ini dikemukakan dalam kekawin Siwaratri kalpa dalam WHD, No. 297, (1992:29), bahwa: “... ri muksa nikana ng kuilem ri teka ning rahina dana ring sabha..." (ketika malam telah berlalu dan dengan munculnya siang, maka hendaknya melakukan sedekah di masyarakat). Yang dapat disedekahkan adalah dari yang megah (uttama) sampai pada hal-hal yang sederhana (nista) sesuai dengan kemampuan dan kesangguan. Dengan pelaksanaan sedekah, maka aspek rohaniah dan jasmaniah dapat dilaksanakan secara berimbang demi terwujudnya doktrin dharma artha yakni moksaartham jagadhita ya ca iti dhama, serta dapat meningkatkan penghayatan dan pengamalan ajaran agama dalam kehidupan aktual di masyarakat. 
Satya Widya : Jurnal Studi Agama Vol. 3 No. 12020

$P$-ISSN : 2623-0534

E-ISSN : 2655-1454

Website Jurnal : https://ejournal.iahntp.ac.id/index.php/satya-widya/index

DOI: https://doi.org/10.33363/swjsa.v3i1 Juni.439

\section{Konstruksi Pemaknaan Simbolik Perayaan Siwaratri}

Hari suci Siwaratri memang memiliki makna yang sangat mendalam, maka iapun menawarkan bahan renungan (kontemplasi) dan kajian yang tidak pernah habis. Terminologi yang sarat makna seperti: papa, punya, brata, jagra, monabrata, upawasa, Lubdhaka, aturu dan atutur menjadi suatu obyek kajian yang cukup menarik untuk direnungkan (Agastia, 1997:58).

Aturu berarti tidur, dan pada hari suci itu dianjurkan untuk tidak tidur. Yang juga menarik adalah bahwa kata tutur merupakan terminologi asli Indonesia yang memiliki makna yang sama dengan smrti (Sansekerta) yang berarti "ingat". Dengan istilah ini dimaksudkan agar pada mala itu senantiasa "eling" atau awarnes. Apabila senantiasa memiliki awarness, maka diharapkan akan dapat melakukan kontrol terhadap obyek-obyek indria dan hendaknya let's conscience to be you guide (biarkan hati nurani sebagai penuntun) dalam mewujudkan prilaku yang positif dalam kehidupan sehari-hari.

Konsep aturu, lupa atau papa dalam Kitab Wrehaspati Tattwa yang memuat dialog antara Bhagawan Wrhaspati dengan Bhatara Iswara mengungkapkan bahwa, seorang yang disebut aturu adalah orang yang terbelenggu oleh obyek indrianya, orang seperti itu disebut juga papa atau lupa (Agastia, 1997:59; Sudharta, 1994:5-6).

Selanjutnya Bhagawan Wrhaspati memberikan solusi untuk mengatasi turu, dan papa adalah dengan senantiasa sadar akan jati diri-Nya maka pikiran menjadi suci dan hening, karena sang Atmalah merasakan suka duka dalam diri. Untuk dapat lepas dari papa dan dari jambangan neraka, Bhatara Iswara mengajarkan kepada manusia, sebuah kata kunci bahwa; yan matutur ikang atma ri jatinya, atau amuter tutur pinahayu (senantiasa menyadari akan hakekat atma yang sejati dan senantiasa membicarakan hal-hal yang mulia).

Hidup manusia dibelenggu oleh bhuta kala atau materi dan waktu. Dalam usaha untuk melepaskan diri dari belenggu bhuta kala itu, manusia hendaknya mendapat keseimbangan jasmani dan rohani, yang bisa dicapai secara gradual dan bertahap, karena banyak hambatan dalam mencapai keseimbangan itu, baik hambatan yang bersifat internal maupun yang bersifat eksternal. Hambatan yang paling sulit diatasi adalah hambatan internal yang ada dalam diri manusia.

Siwaratri pada hakekatnya merupakan suatu ajaran untuk senantiasa membangkitkan perjuangan umat Hindu untuk selalu sadar/awarness atau jagra sehingga senantiasa dapat mengadakan self control terutama terhadap berbagai hambatan yang dialami.

Pemujaan terhadap Dewa Siwa dalam upacara Siwaratri ini, menurut Sudharta (1994:8), justur karena manusia menghadapi segala hambatan dalam menjalani kehidupannya, oleh karena itu memerlukan bantuan Dewa Siwa sebagai pemrelina segala sesuatu yang menghalangi tujuan suci. Dalam konteks ini Dewa Siwa membantu mencapai proses liberasi dari segala belenggu dan tantangan dalam kehidupan manusia. Selain itu Dewa Siwa juga menjadi penuntun dan pelindung manusia menuju hidup penuh kesadaran dan kemuliaan (pencerahan) dengan melenyapkan ke-papa-an atau kesengsaraan. Indikasi orang yang berhasil dalam perjuangan mengatasi ke-papa-an adalah dapat mengendalikan diri dalam makan dan minum yang disimbolkan dengan pelaksanaan upavasa. Orang yang 
dapat mengendalikan diri dalam kata-kata disimbolkan dengan monabrata. Selanjutnya orang yang dapat mengendalikan diri dan senantiasa sadar disimbolkan dengan jagra. Orang yang demikian senantiasa mendapat perlindungan dan waranugraha dari Ida Sang Hyang Widhi Wasa baik di dunia dan di akherat.

Selanjutnya, dalam sumber yang sama dijelaskan bahwa, jika disimak kata Lubdhaka (Bahasa Sansekerta) mendekati arti kata "pemburu", hal ini memberikan gambaran mengenai orang yang mengejar dan mencari sesuatu, yang dalam hal ini dilukiskan dengan binatang (sattwa). Kata sattwa berasal dari kata sat yang berarti "inti atau hakekat", sedangkan kata twa berarti sifat. Dengan demikian makna simbolik yang ditampilkan melalui tokoh Lubdhaka merupakan gambaran atau esensi dari kesadaran yang tertinggi dari pada manusia untuk menemukan kembali hakekat kehidupan yang sesungguhnya. Secara simbolik juga dilukiskan bahwa panglong ping 14 sasih kepitu adalah merupakan puncak dari peredaran masa (malam tergelap), dimana si Lubdhaka secara tidak sengaja telah melepaskan kebiasaannya untuk berbuat hingsa (pembunuhan), yang secara interpretatif menunjukkan pertobatan pada puncak prilaku yang paling kuat. Dalam hubungannya dengan pengendalian diri atau disejajarkan dengan pengertian wyagra (bhs. Jawa Kuno) berasal dari kata wi yang berarti jauh atau utama dan agra berarti puncak. Dengan demikian wyagra lumbrah berarti: "harimau" identik dengan puncak yang utama. Pengendalian diri yang utama dalam yoga kundalini disebutkan bahwa, apabila seseorang telah mencapai tingkatan yang tertinggi, maka semua karmanya akan habis terbakar dan ia akan mencapai liberasi atau kebebasan berupa Pubarbhawa dan moksa (Sudharta, 19945:8-9).

Pada bagian lain, Lubdhaka juga disebutkan naik ke atas pohon maja atau bila untuk menyelamatkan dirinya dari serangan binatang buas, yang merupakan simbolik dari pada keteguhan hati atau ketekunan. Demikian pula dalam konsepsi Hindu Siwa dipandang sebagai dewa yang tertinggi, dan hal ini berarti bahwa, kesadaran yang tertinggi identik dengan usaha mencapai hakikat hidup yang utama (Sudharta, 1994:10).

Dengan demikian dapat dinyatakan bahwa, pelaksanaan Siwaratri sarat dengan makna simbolik yang pada hakikatnya berupaya menuntun manusia untuk mencapai kesadaran yang lebih tinggi serta dapat mengendalikan dirinya untuk senantiasa hidup yang suci dan penuh kesadaran sehingga dapat menghadapi berbagai rintangan dan akhirnya mencapai proses pencerahan dan liberasi.

\section{Konstruksi Pengetahuan dan Pemaknaan Siwaratri: Dari Kontemplasi Menuju Pencerahan}

Umat Hindu mengkonstruksi pengetahuan, keyakinan dan kepercayaan, nilai-nilai dan sikap, tradisi-tradisi, serta pola-pola tindakan tertentu yang diperoleh melalui pelaksanaan /perayaan Siwaratri untuk menyusun satu struktur informasi yang powerfull, dalam arti bermakna, berbasis nilai-nilai, terintegrasi dan selalu aktif memandang untuk selalu dapat direfleksikan kembali (NCSS dalam Sukadi, 2007:11).

Dengan mengacu kepada pemikiran Capra, pengetahuan umat Hindu tentang Siwaratri bukanlah realitas objektif yang ada di luar diri manusia. Pengetahuan yang dimiliki oleh umat Hindu, sebaliknya adalah rekonstruksi aktif dalam pikiran manusia ketika berinteraksi aktif dengan lingkungannya dengan menggunakan struktur pengetahuan awal atau pengalaman yang sudah dimiliki sebelumnya. Dengan demikian, konstruksi yang dipergunakan untuk membangun kembali pengetahuan, nilai-nilai, keyakinan dan tindakan 
Satya Widya : Jurnal Studi Agama Vol. 3 No. 12020

$P$-ISSN : 2623-0534

E-ISSN : 2655-1454

Website Jurnal : https://ejournal.iahntp.ac.id/index.php/satya-widya/index

DOI: https://doi.org/10.33363/swjsa.v3i1 Juni.439

tertentu yang berguna bagi subjek, terutama dilihat dari dimensi proses aktif, yaitu bagaimana pengetahuan, nilai-nilai dan sikap, serta pola tindakan itu dibangun kembali oleh subjek secara aktif dan kemudian diadaptasikan untuk kepentingan ritual dan disiplin diri menuu pencerahan dan liberasi (Farisi, 2005:21).

Ajaran agama yang terdapat dalam perayaan Siwaratri merupakan sebuah konstruksi pengetahuan agama yang terdapat dalam teks keagamaan (sebagaimana termuat dalam kekawin Siwaratrikalpa, dan dengan meminjam pendapat Geertz (1999) bahwa teks keagamaan mengandung aspek dan evaluatif tentang yang baik dan yang buruk, yang boleh dan terlarang, tidak berdosa dan berdosa atau berpahala positif dan berpahala negatif. Hal ini membutuhkan reinterpretasi, revitalisasi, dan (re-) lokalisasi agar berkontekstual secara meruang dan mewaktu. Teks verbal tertulis, di Bali misalnya berwujud aneka jenis lontar, teks verbal lisan berwujud uraian-uraian keagamaan hidup dalam masyarakat. Ada pula teks non-verbal, yakni sistem ritual, tempat suci, dll. Teks verbal berkaitan erat dengan teks nonverbal. Mengingat, bahwa pemahaman atas teks nonverbal didapat lewat teks verbal baik yang tertulis maupun lisan.

Terlepas dari disfungsi agama, fungsi manifes pelaksanaan agama adalah berkaitan dengan segi doktrin, ritual dan aturan prilaku dalam agama. Namun demikian penting pula diketahui bahwa fungsi laten agama. Agama mempunyai fun gsi yang positif baik di tingkat mikro maupun di tingkat makro, menurut Durkheim dapat berfungsi untuk:

"...to make us act, to aids us to live. The believer who has communicated with his god is not merely a man who sees new truths of which the unbeliever is ignorant; he is a man who is stronger" (Durkheim, 1966:464)

Di sini tampak bahwa melalui komunikasi dengan Tuhannya orang yang beriman dapat mengetahui kebenaran yang tidak dapat diketahui oleh orang kafir tetapi juga menjadikan seseorang lebih kuat, sehingga dapat membantunya untuk hidup. Selain itu dari segi makro agama dapat memenuhi kebutuhan masyarakat untuk secara berkala memperkuat perasaan dan ide-ide kolektif yang menjadi ciri dan inti persatuan masyarakat. Melalui upacara yang dilakukan secara teratur oleh masyarakat dapat memelihara rasa kebersamaan dan membina rasa persatuan.

Parson mengatakan, melalui pengungkapan manusia dalam ritus tidak hanya menunjukkan kebersamaan sikap, tetapi juga memperkuat sikap itu. Ritus atau upacara keagamaan dan tindakan pemujaan merupakan tindakan sosial yang memperkuat nilai-nilai kehidupan masyarakat. Bagi individu tindakan pemujaan berarti menyatukan dirinya dalam tatanan kehidupan kelompok dalam hubungan persaudaraan dan dapat menghubungkan diri dengan sumber kekuatan yang omnipotent dan omnipresent, yakni Ida Sang Hyang Widhi Wasa dengan segala manifestasi-Nya.

Dalam pelaksanaan upacara Siwaratri secara mikro paling tidak dapat mencapai pencerahan dan liberasi karena Siwa sebagai manifestasi Tuhan dianggap berfungsi sebagai pelebur atau pemralina kegelapan (awidya). Karena itu melalui pemujaan Siwa pada malam yang paling gelap pada panglong ping 14 diyakini dapat 
memperoleh pencerahan dan dapat mengendalikan diri melalui pelaksanaan brata Siwaratri.

Sesungguhnya pelaksanaan Siwaratri bertumpu pada latihan bathin, bukan pada ritus atau upacara keagamaan. Fenomena yang demikian telah mengedepan dalam kehidupan masyarakat Hindu. Hal mana upacara Siwaratri tidak ditonjolkan dengan upacara yang megah seperti yang tampak pada pelaksanaan hari-hari raya lainnya. Realitas itu memperlihatkan bahwa pemahaman umat telah berada pada track yang benar bahwa, pada malam Purwaning Tilem Kepitu adalah payogan Sang Hyang Siwa, maka umat patut melakukan hal yang sama sebagaimana yang dilakukan oleh Lubdhaka sehingga mencapai kebebasan dari neraka dan memperoleh tempat terhormat di Siwa Loka.

Secara mythologis dinyatakan bahwa, pada Purwaning Tilem Kepitu Sang Hyang Siwa melakukan yoganya, selama semalam penuh. Yoga Sang Hyang Siwa atau kehendak suci dari Ida Sang Hyang Widhi untuk berhubungan dengan jiwa manusia. Hubungan ini akan berhasil bilamana mendapat reaksi dari umatnya dengan mempersiapkan secara lahir dan batin untuk menerima "pangestu" atau anugerah yang dipancarkan oleh Sanghyang Siwa melalui semadi-Nya pada malam itu. Barang siapa yang dapat menerima pangestu itu akan mendapat phahala yang tak ternilai mulianya (Sub Proyek Bimbingan pengelolaan dan Da'wah agama Hindu dan Budha, t.t.,36).

Lubdhaka sebagai seorang pemburu binatang dan dinyatakan banyak dosanya karena sebagai pembunuh, namun karena dapat melakukan yoga semadi pada moment yang tepat (pada saat Sanghyang Siwa melakukan yoga semadhi) maka ia memperoleh liberasi (kesadaran) dari segala dosa serta pencerahan batin bahkan dinyatakan memperoleh sambutan dan kedudukan yang baik di Siwa Loka.

Dalam Kekawin Siwaratri Kalpa karya Mpu Tan Akung, diuraikan bahwa ada beberapa alasan sehingga terbukanya pintu sorga bagi arwah si Lubdhaka, yakni sebagai berikut:

1. Apan diwya dahat tekapnya mawangun dharmadhika mwang brata (sebab sangat baik caranya dalam melaksanakan keutamaan dharma dan brata).

2. Atyanteki renangku denta mamangun brata paramapawitra tan sipi (alangkah senangnya kini hatiku karena engkau melaksanakan brata yang sangat utama tiada tara).

3. Manggeh karana nig samangkana sakeng brata Siwaratri ndatan kalen (adapun sebabnya hingga demikian adalah karena brata Siwaratri tiada lain).

4. Ikang ngaran si Lubdhaka jugang huwus angulahaken wara brata (yang namanya si Lubdhaka saja telah melaksanakan brata yang utama).

Kutipan di atas secara eksplisit memperlihatkan pentingnya brata Siwaratri yang dilaksanakan pada moment yang tepat sehingga diyakini dapat mencapai liberasi (kebebasan) dari dosa-dosa dan membukakan pintu sorga. Renungan melalui perayaan Siwaratri hendaknya mampu mengantarkan pemeluknya untuk lebih menyadari akan eksistensi dirinya sebagai proses peleburan kesadaran pribadinya menuju kepada kesadaran universal. Hal ini disebabkan karena hidup setiap orang 
Satya Widya : Jurnal Studi Agama Vol. 3 No. 12020

$P$-ISSN : 2623-0534

E-ISSN : 2655-1454

Website Jurnal : https://ejournal.iahntp.ac.id/index.php/satya-widya/index

DOI: https://doi.org/10.33363/swjsa.v3i1 Juni.439

dipenuhi oleh Tuhan. Eksistensi (sath) berasal dari sumber semua sath yaitu Tuhan (Brahman). Kebahagiaan atau ananda berasal dari sumber semua ananda yaitu Brahman. Kesadaran atau Chith berasal dari sumber semua Chith, yaitu Brahman. Kita semua adalah penjelmaan dari sath-chith dan ananda, hanya saja kita tidak menyadari dan terpengaruh oleh keterbatasan itu, membayangkan diri sebagai si A dan si B. Ini adalah mitos yang harus dihancurkan agar pencerahan, liberasi dan bahkan kehidupan ilahi dapat dimulai (SSBB dalam Kasturi, 1997:19). Tuhan dalam hal ini Siwa juga mengilhami, menggiatkan, memimpin, dan memenuhi kehidupan semua mahluk, betapapun rumit atau sederhananya susunan jasmani mahluk itu. Dari atom sampai makrokosmos yang terbesar, setiap insan ibarat sungai akan bergerak ke arah muara agar dapat lebur ke dalam lautan kebahagiaan.

Kebahagiaan, kebebasan (liberasi) dari penderitaan, keterbelakangan, ketertindasan (dalam arti luas) adalah dambaan setiap umat manusia. Demikian pula dengan kehidupan yang ilahi adalah nafas setiap mahluk, itu terdiri dari satya (kebenaran), prema (kejujuran), dan ahimsa (tidak menyakiti). Sebab bagaimana mungkin seseorang dapat berbuat tidak adil terhadap yang lain apabila tidak ada orang lain sama sekali. Kebohongan timbul dari rasa takut, dan jika tidak ada orang kedua, tidak ada yang perlu ditakuti. Tidak ada apapun yang lebih dicintai dari pada Diri Yang Sejati (Atma), maka bila semua adalah diri yang sejati (Atma), maka semua akan dicintai sebagaimana mencintai dirinya sendiri. Jika kesadaran ini telah diperoleh maka dengan sendirinya muncul sifat-sifat ilahi dalam kehdiupan seharihari, yang diwarnai oleh sikap saling menghargai, memaafkan, dan saling mengasihi antara sesama mahluk hidup.

Bagaimana cara menempuh kehidupan ilahi? Tidak ada perkumpulan khusus yang berhak memberikan hal itu. Semua usaha untuk menyadari kesatuan di balik semua manifestasi yang beraneka ragam ini adalah suatu langkah di jalan kehidupan ilahi. Seseorang harus mengaduk susu jika ingin memisahkan mentega yang ada di dalamnya, demikian pula kita harus melakukan beberapa tindakan dan proses berpikir agar memperoleh keyakinan yang mendalam mengenai sesuatu. Kehidupan ilahi tidak sedikitpun mengijinkan adanya noda dalam watak seseorang atau kesesatan dalam budinya jadi orang yang mengabdikan dirinya untuk itu ia harus menunjukkan hal ini dengan ajaran atau teladan bukan hanya dengan pidato atau orasi yang hebat untuk mempengaruhi orang lain. Sehubungan dengan hal itu, upaya untuk mencapai liberasi (kesadaran) adalah dengan menghapuskan akar penyebab rasa takut, kecemasan, dan kebodohan. Hanya dengan demikian, mka pribadi orang akan bersinar rasa kahawatir dilenyapkan dengan kepercayaan pada Tuhan, keyakinan bahwa apapun yang terjadi adalah baik bagi kita dan semua terjadi atas kehendak Tuhan. Kemampuan untuk menerima dengan tenang adalah baju baja atau pelindung yang ampuh untuk menghadapi rasa cemas, bukan penanggulangan dengan gagah berani. Kesedihan berasal dari egoisme, perasaan bahwa kita tidak layak diperlakukan demikian jeleknya sehingga kita tidak berdaya. Bila egoisme lenyap, kesedihanpun menghilang. Kebodohan adalah semata-mata kekhilafan karena menganggap badan kita sebagai diri sendiri (SSBB dalam Kasturi, 1997:20). 
Pertanyaan sederhana yang mungkin diajukan, numun sangat sulit untuk memberikan jawaban yang mumuaskan yakni; mungkinkah dapat mencapai liberasi atau mencapai kesadaran ilahi di era kaliyuga ini? Sebagai manusia yang memiliki akal budi,harapan, keyakinan, dan niat untuk kebangkitan menuju kebebasan (Moksa), hal itu masih mungkin dapat dicapai.

Dengan meminjam istilah Fromm (1996:7--16) bahwa harapan merupakan unsur yang sangat penting dalam setiap upaya mengadakan perubahan sosial agar menjadi lebih hidup, lebih sadar, dan lebih berakal. Objek harapan bisa jadi benda (material), namun bisa juga berupa non material seperti; kebahagiaan, kebebasan, keluhuran budi, kesembuhan dan sebagainya. Setiap orang memiliki harapan, jika harapan sirna, maka secara potensial, kehidupan pun musnah. Harapan adalah unsur intrinsik struktur kehidupan, dinamika spirit manusia. Harapan berhubungan erat dengan unsur lain dari struktur kehidupan yakni keyakinan (feith). Keyakinan bukan bentuk lemah dari kepercayaan dan pengetahuan. Ia juga bukan merupakan keyakinan terhadap ini dan itu. Keyakinan adalah kepastian terhadap yang belum terjamin,pengetahuan tentang kemungkinan riil. Keyakinan itu adalah rasional apabila ia menunjuk pada pengetahuan dan kenyataan yang belum dilahirkan, didasarkan atas kemampuan untuk mengetahui dan memahami, menembus permukaan dan melihat intinya. Seperti harapan, keyakinan bukan prediksi masa yang akan datang, ia adalah visi saat ini.

Pernyaaan keyakinan sebagai kepastian memerlukan kualifikasi, itu adalah kepastian tentang realitas dari kemungkinan-tetapi kapastian dan bukan ramalan yang dipersoalkan. Dalam ajaran Hindu keyakinan yang dapat disepadankan artinya dengan keyakinan adalah Sraddha. Sraddha dalam ajaran agama Hindu dikenal dengan istilah Panca Sraddha, yakni kepercayaan kepada Brahman, atman, karman, Pubarbhawa, dan moksa.

Sraddha dalam ajaran agama Hindu diharapkan dapat menjadi alat yang mampu menstimulir manusia untuk senantiasa melakukan transformasi diri dan realitas kehidupan menuju arah kehidupan yang lebih agung. Manusia dan masyarakat dibangkitkan setiap saat dalam tindakan, harapan dan keyakinan di sini dan kini. Setiap tindakan cinta kasih, kesadaran, ketulusan, keharuan dan upaya untuk selalu dekat dekat Ida sanghyang Widhi Wasa dan segala manifestasinya adalah sebuah kebangkitan. Setiap eksistensi moment menghadapkan kepada alternatif-alternatif antara kebangkitan dan kematian; setiap tindakan malas, serakah, mementingkan diri sendiri, dan semakin jauh dari Ida sanghyang Widhi Wasa adalah sebuah kematian. Setiap saat kita memberikan jawaban. Jawaban ini tidak terletak pada apa yang kita katakan atau pikirkan, melainkan pada "kita", bagaimana akan bertindak dan ke arah mana akan bergerak.

\section{Simpulan}

Demikian ajaran Siwaratri sebagai salah satu ritual Hindu yang sarat dengan pengetahuan keagamaan nilai-nilai tattwa, etika dan ritual secra makna simbolik baik yang menyangkut proses ritualnya maupun dalam pelaksanaan brata (jagra, upavasa dan monabrata) yang dilaksanakan dalam rangkaian pemujaan kepada Siwa. Pelaksanaan Siwaratri bagi umat Hindu lebih ditekankan pada aspek filosofis dan 
Satya Widya : Jurnal Studi Agama Vol. 3 No. 12020

$P-I S S N$ : 2623-0534

E-ISSN : 2655-1454

Website Jurnal : https://ejournal.iahntp.ac.id/index.php/satya-widya/index

DOI: https://doi.org/10.33363/swjsa.v3i1 Juni.439

etikanya dari pada penekanan pada aspek ritualnya, Hal ini disebabkan karena pelaksanaan Siwaratri sebagai momen untuk latihan batin dan upaya pengendalian diri melalui pelaksanaan brata Siwaratri dalam upaya mencapai liberasi dan pencerahan manusia dari kegelapan(ratri) melalui bantuan "pangestu" Dewa Siwa yang sedang melakukan yoga semadi.

Penekanan pada aspek tattwa dan etika ini menunjukkkan bahwa pelaksanaan Siwaratri menunjukkan adanya pergeseran dari ritualisme menuju tattwa pada kahikatnya tumbuh dari kesadaran manusia yang paling dalam untuk lebih mendekatkan diri dengan Ida Sanghyang Widhi Wasa.Penggunaan perayaan Siwaratri sebagai wahana peningkatan kualitas moral yang mengarah pada upaya terwujudnya pencerahan dalam diri umat Hindu menuju pembebasan (dalam arti luas). Semua proses tersebut dapat dianggap sebagai proses internalisasi nilai-nilai ajaran agama dalam pelaksanaan Siwaratri untuk mengembangan wawasan (pengatahuan) keagamaan dan bahkan sebagai media pembentukan prilaku keagamaan yang lebih arif, etik, dan lebih humanis. Proses internalissai nilai-nilai agama dan membangun sebuah pemaknaan baru dalam konteks perayaan Siwaratri, pada dasarnya dapat dipandang sebagai proses konstruksi, baik konstruksi agama, sosial, dan budaya menuju sebuah "kebangkitan" (pencerahan).

\section{DAFTAR PUSAKA}

Agastia, IBG, 1997, Memahami Makna Siwaratri, Yayasan Dharma Sastra, Denpasar.

Durkheim, Emile, 1966, The Elementary Form of the Religious Life, diterjemahkan dari Bahasa Perancis oleh Joseph ward Swain, New York, the Free Press.

Farisi, Imam M.2005. "Rekonstruksi Dasar-dasar Pemikiran Pendidikan IPS-SD Berdasarkan Perspektif Konstruktivisme”Disertasi (tidak dipublikasikan): Bandung: UPI.

Fromm, Erich, 1996, Revolusi Harapan: Menuju Masyarakat Teknologi yang Manusiawi, Pustaka Pelajar, Yogyakarta.

Kasturi, 1997. Wejangan-wejangan Bhagawan Sri Satya Sai Baba (Sathya Sai Speaks Volume 1), Jakarta:Yayasan Bhagawan Sri Satya Sai Baba

Kasturi, 2002. China Katha III : Kisah dan Perumpamaan Yayasan Bhagawan Sri Satya Sai Baba (Sathya Sai Speaks Volume 1), Jakarta:Yayasan Bhagawan Sri Satya Sai Baba

Koentjaraningrat, 1974, Pengantar Antropologi, Cetakan V, Akasara Baru, Jakarta. 
Light, Donald, Suzanne Keiler dan Craig Colhoun, 1989, Sociology, New York,: Alpred AA. Knopf.

Mantra, I Ketut (translator), 1999, Wejangan Bhagawan Sri Satya Sai Baba, Curahan Air Keabadian (Amrta Varsini), Paramita, Surabaya.

Nottingham, Elizabeth, K., 1994, Agama dan Masyarakat: Suatu Pengantar Sosiologi Agama, Raja Grafindo Persada, Jakarta.

Sub Proyek Bimbingan Pengolahan dan Da'wah agama Hindu dan Budha, t.t., Hari Raya/Rerahinan Bagi Umat Hindu, Direktorat Jenderal Bimas Hindu dan Budha, Departemen Agama RI. Jakarta.

Sudharta, Tjok Rai, 1994, Siwaratri: Makna dan Upacara, Upada Sastra, Denpasar.

Sukadi, 2006, "Pendidikan IPS sebagai Rekonstruksi Pengalaman Budaya Berbasis Ideologi Tri Hita Karana (Studi Etnografi Tentang Pengaruh Masyarakat Terhadap Program Pendidikan IPS Pada SMU 1 Ubud Bali “, (Disertasi Sekolah Pascasarjana Universitas Pendidikan Indoensia) Bandung. 